\title{
Shape Memory Polyurethane Biocomposites Based on Toughened Polycaprolactone Promoted by Nano-Chitosan
}

\author{
Arvind Gupta $@$ and Beom Soo Kim *๑ \\ Department of Chemical Engineering, Chungbuk National University, Cheongju, Chungbuk 28644, Korea; \\ myarvind2003@gmail.com \\ * Correspondence: bskim@chungbuk.ac.kr; Tel.: +82-43-261-2372
}

Received: 17 January 2019; Accepted: 4 February 2019; Published: 7 February 2019

\begin{abstract}
The distinctive ability to remember their original form after partial or complete deformation makes shape memory polymers remarkable materials for several engineering and biomedical applications. In the present work, the development of a polycaprolactone based toughened shape memory polyurethane biocomposite promoted by in situ incorporation of chitosan flakes has been demonstrated. The chitosan flakes were homogeneously present in the polymer matrix in the form of nanoflakes, as confirmed by the electron microscopic analysis and probably developed a crosslinked node that promoted toughness ( $a>500 \%$ elongation at break) and led to $a \sim 130 \%$ increment in ultimate tensile strength, as analyzed using a universal testing machine. During a tensile pull, $\mathrm{X}$-ray analysis revealed the development of crystallites, which resulted from a stress induced crystallization process that may retain the shape and melting of the crystallites stimulating shape recovery (with $a$ $\sim 100 \%$ shape recovery ratio), even after permanent deformation. The biodegradable polyurethane biocomposite also demonstrates relatively high thermal stability $\left(T_{\max }\right.$ at $\left.\sim 360{ }^{\circ} \mathrm{C}\right)$. The prepared material possesses a unique shape memory behavior, even after permanent deformation up to $a>500 \%$ strain, which may have great potential in several biomedical applications.
\end{abstract}

Keywords: chitosan; polycaprolactone; shape memory; stretchability; polyurethane; biocomposite

\section{Introduction}

The distinctive ability to remember their original form after partial or complete deformation makes the shape memory polymers (SMP) remarkable materials for several engineering and biomedical applications. Along with the widely known shape memory alloy, Nitinol (Nickel-Titanium Naval Ordnance Laboratory) [1], various polymers such as polyacrylates [2], polyimides [3], styrene-butadiene copolymers [4,5], polyurethane (PU) [6], polystyrene [7], etc., are known to have a shape memory ability on application of an external stimulus, such as $\mathrm{pH}$, electrical, mechanical, hydration, magnetic, heat, light, etc. $[8,9]$. Among these polymers, polyurethane is found to be a versatile material due to its extraordinary characteristics, such as its relatively high toughness, light weight, tolerance to strain, high strength and elongation at break, abrasion resistance, low cost, and easy processability; polyurethane has applications in various domains, ranging from electronic packaging, food packaging, biomedical, aerospace, automobiles, textiles, energy, etc., to commodity applications [10,11].

Polyurethanes are a class of polymers with inherent two-phase separated domains due to a microphase inhomogeneity containing a urethane bond between an alternating polymer block of hard and soft segments, wherein diisocyanate is a hard segment connected to the flexible soft segments made of polyether or polyester diol chains. The presence of a hard segment is responsible for remembering 
the original shape, whereas the soft segment stores the energy for dissipation and provides the desired force, allowing polyurethane to return to its original form. Herein, the soft segments, i.e., polyol, can broadly be classified as carbonate based (i.e., polyhexamethylene carbonate diol) [12], ether based (i.e., polytetrahydrofuran diol) [13], and ester based (i.e., polycaprolactone diol) [14]. These conventional polyols are generally obtained from petroleum-based resources, and only some of them are biodegradable [15].

It is now recognized by the scientific community that the biopolymers, biobased and biodegradable polymers, have the potential to replace existing petroleum based non-biodegradable polymers and may thus be considered promising future materials [16]. These polymers include polylactic acid (PLA), polycaprolactone (PCL), polyglycolic acid (PGA), polyhydroxybutyrate (PHB), etc., which have been found to be useful in applications ranging from biomedical to automobile, along with day to day applications according to the properties of the polymers [17]. For several areas, such as tissue engineering, orthopedic implants, or other biomedical applications, PCL has been found to be one of the most promising polymeric materials due to its lower melting temperature, easy processability, biodegradability, lower glass transition temperature, nontoxicity, relatively higher thermal degradation temperature, etc. [18]. However, it has been found that PCL has inherently unique characteristics, and certain limitations of this polymer restrict its direct use in the targeted applications [19]. The desired applications often require specific properties which are difficult to determine from a pristine polymer.

In order to serve their purpose, biodegradable polymers such as PCL can be used in combination with each other. Moreover, different techniques, such as blending of polymers [20], copolymerization [21], fabrication of biocomposite with biofillers [22,23], grafting [24], crosslinking [25], etc., can be used to tailor the properties of the PCL based final product. Fabrication of the composite with fillers via blending, in situ polymerization [26], and reinforcement [27], is a promising approach to tailor the final product's properties, such as mechanical strength, toughness, stiffness, biodegradability, and behavior of shape memory. Several organic and inorganic materials, such as carbon based fillers, chitosan [28], lignin [29], graphene [30], cellulose [31], magnetic nanoparticles [32], and metal nanoparticles [33] can be used as fillers for the development of biodegradable polyurethanes. Among these fillers, chitosan, which is often used as both filler and polymer matrix, is a promising biopolymer. Chitosan, which can be utilized in biomedical applications, is recognized as nontoxic, biodegradable, and antibacterial in nature. Chitosan can be produced using a process of chitin deacetylation, which is derived from the bioresource.

It is known that chitosan has a melting point near degradation temperature, which restricts its thermal processing both in its pristine form and with other polymers. The presence of free amino functional groups in the chitosan molecule aids in solubilizing it in acidic media by functional protonation. Additionally, it is challenging to obtain a uniform distribution of chitosan throughout the polymer matrix due to its hydrophilic nature. Several researchers have developed different process to modify chitosan and use it in biocomposite fabrication $[34,35]$. Various research groups are working worldwide to utilize chitosan in shape memory applications. By incorporating bioactive glass nanoparticles obtained from the sol-gel process, Leite et al. [36] have synthesized chitosan spheres. They reported a shape memory effect triggered by hydration and used for healing bones and controlling drug release. Bao et al. [37] have developed chitosan functionalized poly(lactic-co-glycolic acid) (PLGA) microspheres containing lysozyme. They have used high intensity focused ultrasound to stimulate the shape memory effect. Zhang et al. [38] used microwaves as a shape memory stimulant in PCL foam and found improvement in the recovery speed. Similarly, Shou et al. [39] have developed near infrared light (NIR) responsive shape memory films via photo-initiated polymerization of PCL with acryloyl terminal groups in the presence of gold nanorods. They conceptualized a controllable shape memory PCL, embedded with a gold nanorod film, that can actuate in a physiological temperature using NIR situated at a remote place. However, as per our knowledge, the use of chitosan as a filler in a PCL matrix by in situ reaction for a shape memory application has not been explored. 
Therefore, the present work is focused on the development of a thermo-responsive shape memory biodegradable PCL based polyurethane and its composites. Herein, the chitosan flakes (nm to $\mu \mathrm{m}$ scale) react with the PCL diol, thereby providing a crosslinking point in the polymer matrix, which potentially enhances the shape memory effect along with the mechanical properties of the PCL based polyurethane. Several techniques, such as universal testing machine (UTM), thermogravimetric analysis (TGA), differential scanning calorimetry (DSC), fourier transform infrared (FTIR), and X-ray diffraction (XRD) have been used to characterize the prepared polyurethane biocomposites.

\section{Materials and Methods}

\subsection{Materials}

Chitosan was derived from shrimp shells with $\geq 75 \%$ deacetylation, which were obtained from Sigma Aldrich (Reykjavik, Iceland). PCL diol with an average molecular weight (Mn) of $2000 \mathrm{~g} / \mathrm{mole}$ was purchased from Sigma Aldrich (Hong kong, China). 1,6-hexamethylene diisocynate (HMDI) was supplied by Daejung (Siheung, Korea). Dibutyltin dilaurate (DBDTL), used as catalyst, was provided by Sigma (St. Louis, MO, USA). Acetone and chloroform were procured from J.T. Baker Avantor (Center Valley, PA, USA). N,N-Dimethylformamide (DMF) and 1,4-butanediol (BDO) were purchased from Tedia Company Inc. (Fairfield, OH, USA) and Aldrich (Steinheim, Germany), respectively. Hydrogen peroxide $\left(\mathrm{H}_{2} \mathrm{O}_{2}\right)$ was received from Samchun (Seoul, Korea). All the received chemicals were used without further purification, unless otherwise stated.

\subsection{Preparation of Polyurethane Biocomposite}

It is known that chitosan is available in the form of relatively large flakes and insoluble in DMF, due to strong glycosidic linkage in the backbone molecules. Initially, $10 \mathrm{~g}$ of chitosan was added to $100 \mathrm{~mL}$ of hydrogen peroxide (30\%) by stirring (MS-DMS633, Mtops, Yangju, Korea) at $40{ }^{\circ} \mathrm{C}$ for $24 \mathrm{~h}$ to increase the dispersion and allow for swelling. After swelling, the prepared slurry was added to a sufficient amount of acetone to precipitate the chitosan. The swelling and precipitation processes are known to reduce the size of the obtained flakes and weaken glycosidic linkages. The obtained purified chitosan was washed with an adequate amount of deionized water several times until a neutral $\mathrm{pH}$ was obtained; this process was followed by freeze drying (IIshin Lab Co. Ltd., Seoul, Korea) for $24 \mathrm{~h}$. The resulting chitosan (the required amount) was allowed to swell in $10 \mathrm{~mL}$ of DMF for $24 \mathrm{~h}$ in order to use it for further biocomposite fabrication.

The Chitosan promoted PCL based shape memory polyurethane biocomposite was prepared according to the following steps. The required amount of PCL diol was dropped into a two-neck round-bottom flask equipped with a magnetic stirring bar and an inert environment kept at $40{ }^{\circ} \mathrm{C}$ on a stirrer with a hot mantle. Subsequently, the predetermined amount of chitosan swollen in DMF was added to the flask to maintain at $5 \%, 7.5 \%, 10 \%$, and $20 \%$ against the PCL. After dissolution of the PCL, the temperature was raised to $80^{\circ} \mathrm{C}$, and stirring was maintained at $200 \mathrm{rpm}$. HMDI was added to the solution dropwise under inert conditions, along with a few drops of DBTDL as a catalyst. The reaction continued for $2 \mathrm{~h}$ to form a diisocynate terminated prepolymer. BDO was added to the reaction system as a chain extender, and stirring continued. The chain extension was followed by the addition of chloroform under a reflux condition to reduce the viscosity of the reaction system. The solution was then poured on a polypropylene tray. The solution tray was kept in a fume hood to allow the evaporation of the chloroform, followed by drying in a vacuum oven at $80{ }^{\circ} \mathrm{C}$ for $24 \mathrm{~h}$. Additionally, PCL polyurethane without chitosan was prepared by following the same procedure as described above for the comparison. All samples was prepared by maintaining the $\mathrm{NCO}: \mathrm{OH}$ final ratio as 1:1.1. The obtained film was stored in a refrigerator for further characterization. The polyurethane biocomposites with 5\%,7.5\%, 10\%, and 20\% chitosan content were denoted as PCL-PU-M5, PCL-PU-M7.5, PCL-PU-M10, and PCL-PU-M20, respectively, while neat PCL polyurethane was denoted as PCL-PU. 


\subsection{Characterization}

Fourier transform infrared (FTIR) spectroscopy spectra were obtained on a Nicolet IR 200 (Thermo Scientific, Waltham, MA, USA) instrument at room temperature. The spectra of the thin film were recorded against air as reference in the range between 4000 and $600 \mathrm{~cm}^{-1}$ after 64 scans with $4 \mathrm{~cm}^{-1}$ resolution.

Differential scanning calorimetry (DSC Q2000, TA Instruments, New Castle, DE, USA) was used to measure melting, crystallization, and glass transitions of the sample under an inert environment. The pre-weighed sample (5-10 mg) was heated from $25^{\circ} \mathrm{C}$ to $150{ }^{\circ} \mathrm{C}$ with a rate of $10^{\circ} \mathrm{C} / \mathrm{min}$ and kept under isothermal conditions for $5 \mathrm{~min}$ to eliminate its thermal history. The sample was then cooled to $25{ }^{\circ} \mathrm{C}$ with a rate of $10{ }^{\circ} \mathrm{C} / \mathrm{min}$, kept isothermal for $5 \mathrm{~min}$, and heated again to $150{ }^{\circ} \mathrm{C}$ with the same rate.

Thermogravimetric analysis (D-TGA, SDT 2960, TA Instruments) was carried out by heating 2-5 $\mathrm{mg}$ of the sample from room temperature to $500{ }^{\circ} \mathrm{C}$ with a rate of $10{ }^{\circ} \mathrm{C} / \mathrm{min}$ under a $\mathrm{N}_{2}$ environment.

X-ray diffraction (XRD) spectra were recorded using an automated multipurpose X-ray diffractometer (JP/SmartLab, 9kW, Rigaku, Tokyo, Japan) equipped with copper (Cu) $\mathrm{K} \alpha$ radiation $(1.540593 \AA)$ as an X-ray source $(40 \mathrm{kV}, 200 \mathrm{~mA})$ with a monochromatic filter along with a detector (SC-70). The samples were analyzed in the range of $5-30^{\circ}$ at a scan rate of $2^{\circ} / \mathrm{min}$ with a $0.02^{\circ}$ resolution.

Contact angle measurement equipment (Model GSM) supplied by Surfacetech Co. Ltd. (Gwangju, Korea) was used to measure the contact angle of $2 \mu \mathrm{L}$ of deionized water dropped on the surface of the prepared biocomposites. The films were pasted on a cleaned glass slide prior to measurement, and the angle was determined after 2 min of drop stabilization. The contact angles were determined from at least three different regions on each sample surface along with standard deviation.

Tensile strength and percent elongation of the prepared biocomposite samples were analyzed using a universal testing machine (UTM) (LRK-5kN, Cometech, QC-M2014, NTS Technology Co. Ltd. Chengdu, China). The specimens ( $5 \mathrm{~mm}$ width, $0.5-1.0 \mathrm{~mm}$ thickness, and $20 \mathrm{~mm}$ gauge length) were fixed and analyzed under a UTM equipped with a $5 \mathrm{kN}$ load cell at a fixed cross-head speed of $5 \mathrm{~mm} / \mathrm{min}$ in tensile mode. The data obtained were analyzed using AMIS 1.1.6 software and reported as the mean of at least five replicates of each sample along with standard deviation.

The topography of the fractured samples was examined using a field emission scanning electron microscope (FESEM). The samples were gold coated in a sputtering unit and characterized using FESEM (Ultra Plus, Zeiss $\mathrm{GmbH}$ ) at an accelerating voltage of $3 \mathrm{kV}$ after placing it on a carbon tape. The micrograph was analyzed using Gwyddion version 2.25 software (Cszech Metrology Institute, Brno, Cszech Republic).

The gel content, formed due to the formation of a cross-linked three-dimensional network, was quantified using Equation (1):

$$
\text { Gel content }(\%)=\frac{W_{g e l}}{W_{i}} \times 100
$$

where $W_{i}$ and $W_{g e l}$ represent the initial weight of the prepared biocomposite and the weight of dried gel, respectively, after washing with chloroform and then vacuum drying.

The shape memory behavior of the prepared biocomposite was analyzed by performing a tensile test in warm water $\left(50-60{ }^{\circ} \mathrm{C}\right)$ and hot oven $\left(50{ }^{\circ} \mathrm{C}\right)$ conditions. The test was conducted in two environments: (1) Tensile pull and recovery in warm water, and (2) shape setting and recovery in a hot air condition. The sample was deformed by a tensile pull at $50{ }^{\circ} \mathrm{C}$ until a $100 \%$ strain was achieved. Next, the stretched shape was fixed by cooling the sample to $20{ }^{\circ} \mathrm{C}$ for $5 \mathrm{~min}$, and the length was measured. The stretched and fixed sample was dropped in warm water $\left(50-60{ }^{\circ} \mathrm{C}\right)$, and the length was 
measured after the recovery of the sample from the water. The shape fixing ratio and shape recovery ratio were calculated as per the following equations:

$$
\begin{gathered}
\text { Shape fixing ratio }\left(R_{f}\right)=\frac{\left(L_{s}-L_{i}\right)}{L_{i}} \times 100 \\
\text { Shape recovery ratio }\left(R_{r}\right)=\frac{\left(L_{o}-L_{f}\right)}{L_{i}} \times 100
\end{gathered}
$$

where $L_{0}, L_{s}, L_{f}$, and $L_{i}$ represent the length of the sample after stress, the length of the sample after the release of stress, the length of the recovered sample, and the initial length of the sample, respectively.

\section{Results and Discussion}

\subsection{Synthesis of the PCL Based Polyurethane Biocomposite}

The molecular functional groups in the PCL-PU and PCL-PU-chitosan biocomposites were examined using FTIR. The spectra, shown in Figure 1, display the characteristic peaks for the PCL-PU and chitosan. The PCL-PU characteristic peaks at $1732 \mathrm{~cm}^{-1}, 2947 \mathrm{~cm}^{-1}$, and $3332 \mathrm{~cm}^{-1}$ are assigned to the stretching vibration of the carbonyl group, the aliphatic $\mathrm{C}-\mathrm{H}$ bond, and the $\mathrm{N}-\mathrm{H}$ bond, respectively [40]. The band at $3442 \mathrm{~cm}^{-1}$ corresponds to the $\mathrm{N}-\mathrm{H}$ and $\mathrm{OH}$ stretching vibration, whereas peaks at $2947 \mathrm{~cm}^{-1}$ and $2868 \mathrm{~cm}^{-1}$ are related, respectively, to the $\mathrm{C}-\mathrm{H}$ symmetric and asymmetric stretching in chitosan. The bands around $1658 \mathrm{~cm}^{-1}, 1571 \mathrm{~cm}^{-1}$, and $1326 \mathrm{~cm}^{-1}$ correspond to the $\mathrm{C}=\mathrm{O}$ stretching of amide $\mathrm{I}$, the $\mathrm{N}-\mathrm{H}$ bending of amide II, and the $\mathrm{C}-\mathrm{N}$ stretching of amide III of the chitosan acetyl group, respectively. The peaks merged between $1195 \mathrm{~cm}^{-1}$ and $936 \mathrm{~cm}^{-1} \mathrm{are}^{-}$ related to the asymmetric stretching of the $\mathrm{C}-\mathrm{O}-\mathrm{C}$ backbone and the skeletal $\mathrm{C}-\mathrm{O}$ stretching in pristine chitosan, respectively [41]. In the case of PCL-PU and other biocomposites, the peaks corresponding to the $\mathrm{C}-\mathrm{N}$ stretching and $\mathrm{N}-\mathrm{H}$ in-plane bending in the $\mathrm{C}-\mathrm{N}-\mathrm{H}$ functional group are located between $1643 \mathrm{~cm}^{-1}$ and $1504 \mathrm{~cm}^{-1}$. A shoulder found on the absorption peak is attributed to the carbonyl group in PCL-PU. The peak at $1732-1724 \mathrm{~cm}^{-1}$ corresponds to the vibration of the amide group due to the urethane block and chitosan molecules. The stretching band at $3520 \mathrm{~cm}^{-1}$ corresponds to the hydroxyl functional group in PCL diol (not shown in the figure), which disappeared, while a new band, attributed to the N-H stretching, appears at $3332 \mathrm{~cm}^{-1}$, thereby confirming the formation of polyurethane. The presence of peaks related to PCL and chitosan in the prepared biocomposites confirms the formation of polyurethane and chitosan biocomposites.

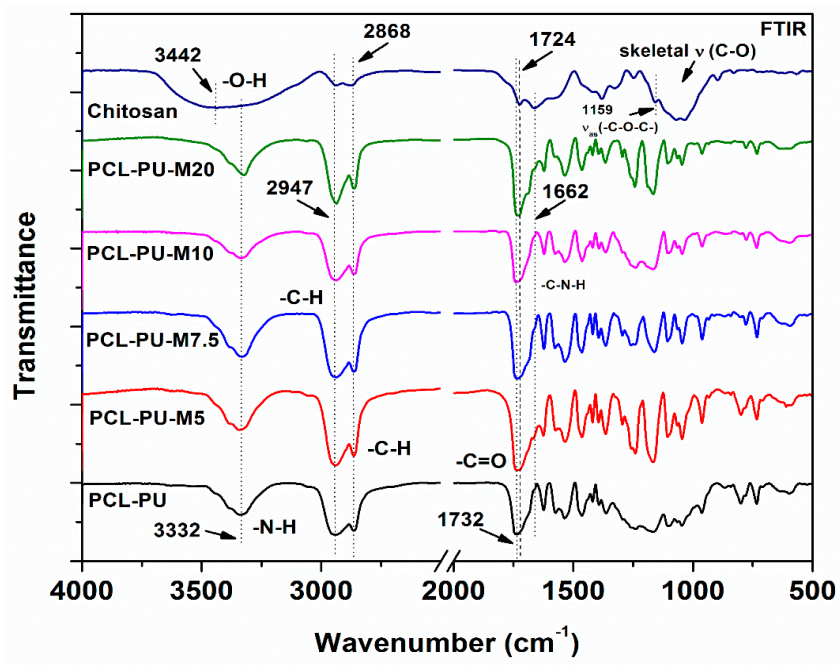

Figure 1. FTIR spectra of Chitosan, polycaprolactone-polyurethane (PCL-PU), and PCL-PUChitosan biocomposites. 


\subsection{Thermal Transitions of Prepared Polyurethane Biocomposites}

The prepared PCL based polyurethane biocomposites were analyzed using DSC, and the thermograms are shown in Figure 2. The heating cycle (Figure 2a) of the biocomposite shows the presence of PCL in crystalline form, with a melting temperature around $40{ }^{\circ} \mathrm{C}$. The melting temperature of biocomposites is found to be the same with PCL-PU, whereas the enthalpy of melting is reduced from $23.7 \mathrm{~J} / \mathrm{g}$ to $11.0 \mathrm{~J} / \mathrm{g}$ as the content of chitosan in the polymer matrix is increased. The reduction in the melting enthalpy suggests a reduction in the crystallinity of the PCL with increasing chitosan content. The presence of chitosan possibly hinders PCL chain mobility, thereby restricting the orientation of chains and forming a crystalline domain, which may be responsible for the reduction in the crystallinity of the biocomposite. Chitosan nano-sized flakes are connected to PCL chains, which form the crosslinking point in the polyurethane system, resulting in an increased amorphous domain. In the case of $20 \%$ chitosan content, the melting temperature of the biocomposite is higher $\left(46.7^{\circ} \mathrm{C}\right)$, which could be attributed to the phase separation of the PCL and chitosan molecules, and the crystalline domain is reduced to $11.0 \mathrm{~J} / \mathrm{g}$. The exothermic peak of the biocomposite in the cooling cycle is found to be shifted towards a lower temperature, as presented in Figure $2 b$. The reduction in the melt crystallization temperature from $2.0^{\circ} \mathrm{C}$ for PCL-PU to $-9.6{ }^{\circ} \mathrm{C}$ for PCL-PU-M10 suggests that the PCL chains in biocomposites need less energy to be crystallized. However the enthalpy of crystallization is reduced from $22.6 \mathrm{~J} / \mathrm{g}$ to $8.3 \mathrm{~J} / \mathrm{g}$, which could be due to the anti-nucleation effect of the chitosan flakes.

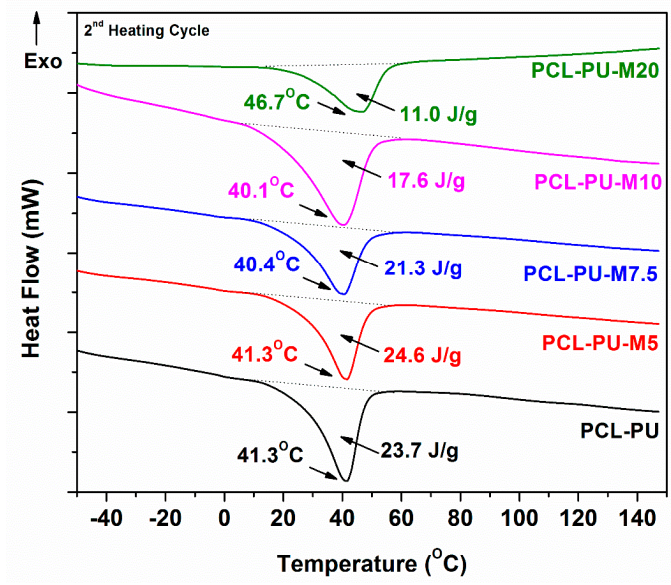

(a)

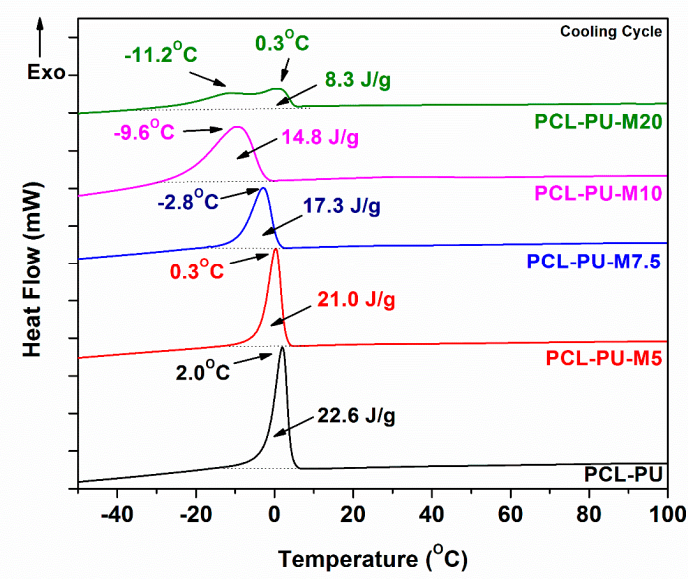

(b)

Figure 2. Differential scanning calorimetry (DSC) thermograms: (a) Second heating and (b) cooling cycle of the PCL-PU and PCL-PU-Chitosan biocomposites.

\subsection{X-ray and Contact Angle Measurements}

The biocomposite was characterized using X-ray diffraction spectroscopy, as shown in the Figure 3a. The characteristic peaks for PCL at $21.3^{\circ}$ and $23.6^{\circ}$ correspond to the (110) and (200) planes of the PCL crystal, whereas the peak at $19.3^{\circ}$ is related to the (110) plane of the chitosan micro crystalline domain reflection $[42,43]$. The peak corresponding to chitosan has a significantly lower intensity in PCL-PU polyurethane biocomposites, whereas it is visible in the biocomposite with $20 \%$ chitosan content, indicating the presence of phase separated domains. No peak shifting was observed, indicating no change in the crystal structure of the PCL and chitosan. 


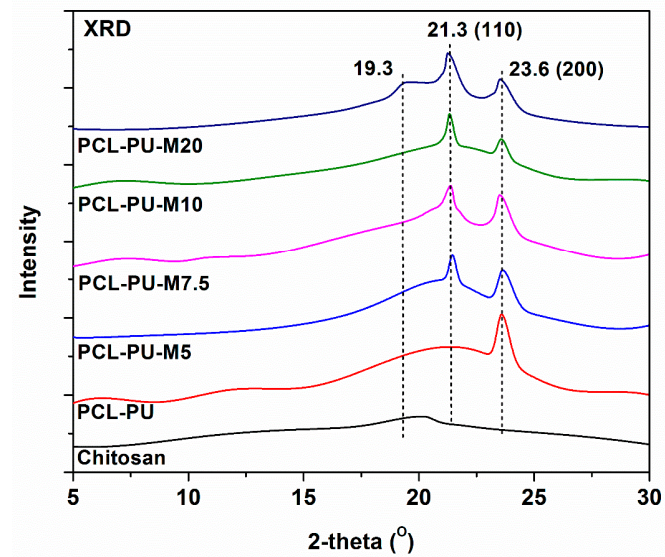

(a)

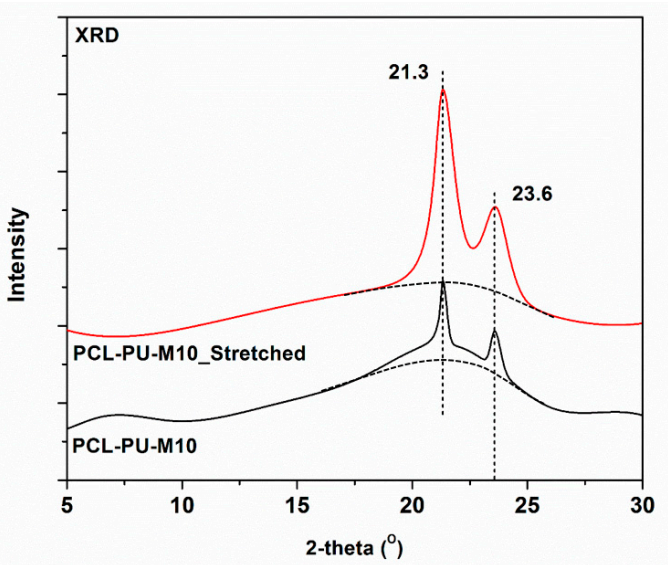

(b)

Figure 3. (a) X-ray diffraction of the PCL-PU and PCL-PU-Chitosan biocomposite and (b) X-ray diffraction comparison of the stretched and non-stretched biocomposite sample.

Contact angle measurement of the prepared biocomposites was employed to understand their interaction with water molecules. The data are presented in Figure 4, and the contact angle was found to increase from around $69^{\circ}$ to $\sim 95^{\circ}$, alongside the increase in the content of chitosan from $0 \%$ to $10 \%$. It is known that wettability is based on the chemical composition, surface topography, and surface free energy of the substance. As the chitosan flake content increases in the biocomposite, the contact angle gradually increases, possibly due to the reduction in surface free energy. The presence of chitosan flakes also affects the surface roughness, which may lead to an increase in the water contact angle. It is observed that the contact angle reduces to $\sim 80^{\circ}$ in a case of $20 \%$ chitosan, suggesting phase separation and a reduction in hydrophobicity.

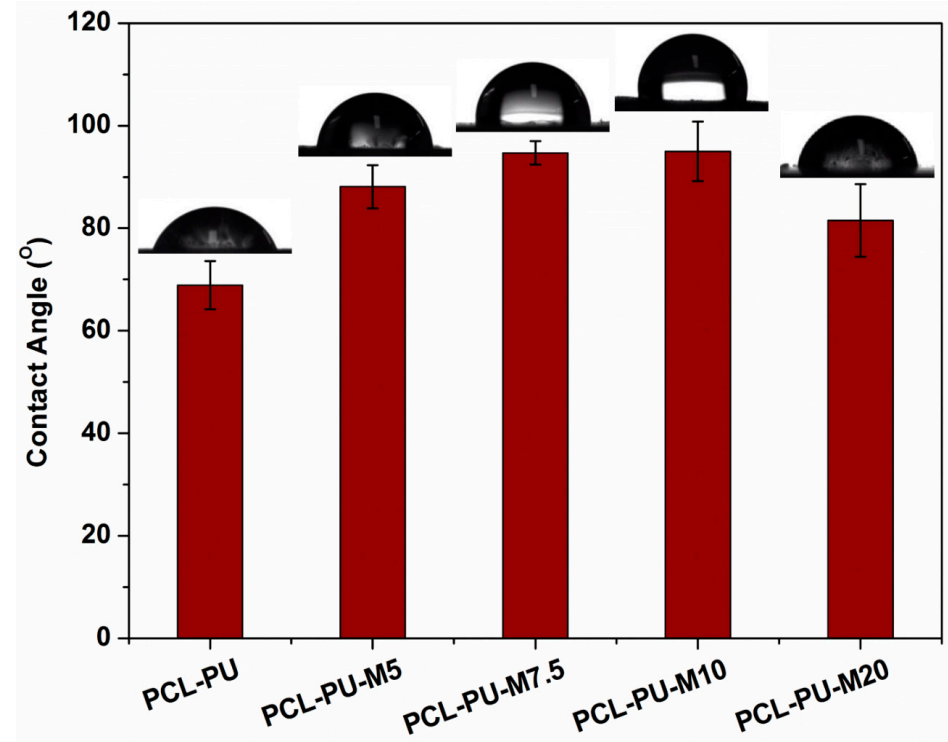

Figure 4. Contact angle measurement of PCL-PU and PCL-PU-Chitosan biocomposites.

\subsection{Mechanical Properties of Polyurethane Biocomposites}

The presence of nano-sized chitosan flakes influences the mechanical properties of the prepared polyurethane biocomposites. It is found that chitosan nanoflakes provide crosslink sites, thereby providing strength and imparting shape memory properties to the polyurethane biocomposite. The representative load-elongation curve and ultimate tensile strength (UTS), along with the elongation at break for PCL-PU and PCL-PU-Chitosan polyurethane biocomposites, are shown in Figure 5a,b. 
The UTS for PCL-PU was found to be $5.2 \mathrm{MPa}$, which increases by approximately $130 \%$ and reaches $12 \mathrm{MPa}$ for the PCL-PU-M10 composite. The strain hardening due to the strong interfacial bonding between the chitosan and PCL chains and the presence of chitosan nano-sized flakes possibly resist the mechanical pull after a certain elongation, ultimately resulting in increased UTS. The elongation at break for PCL-PU was found to be $102 \%$, which increases to $598 \%$ after the addition of $10 \%$ chitosan in the polyurethane biocomposite, indicating a significant improvement in the ductility of the PCL-PU biocomposite with integration of chitosan flakes. The increase in elongation could be the result of the uncoiling of coiled PCL chains present in the polyurethane biocomposite. It is also known that enhancement in the elongation at break or ductility delays the fracture, which reduces the risk of abrupt mechanical failure of the polyurethane biocomposite. As reported [44], the use of chitosan as a filler may improve the UTS of the polymer matrix with compromising elongation at break, whereas an increase in tensile strength along with elongation at break is observed in the present study. Increased elongation at break could be due to the chemical interaction of chitosan nanoflakes with PCL chains, which increase the coiling of the PCL chains at particular crosslink sites. The integration of chitosan with PCL chains can act as a bridge between the uncoiling and sliding chains, thereby lengthening the breakage process. However, in the case of PCL-PU-M20, the elongation at break is reduced to $5.8 \%$. The increased content of chitosan (20\%) in the PCL based polyurethane matrix ensures an improvement of $\sim 21 \%$ in tensile strength compared to PCL-PU. However, the presence of chitosan in higher amounts may induce voids during the elongation process, ultimately resulting in breakage and a rupture of bonds leading to a reduction in the elongation at break.

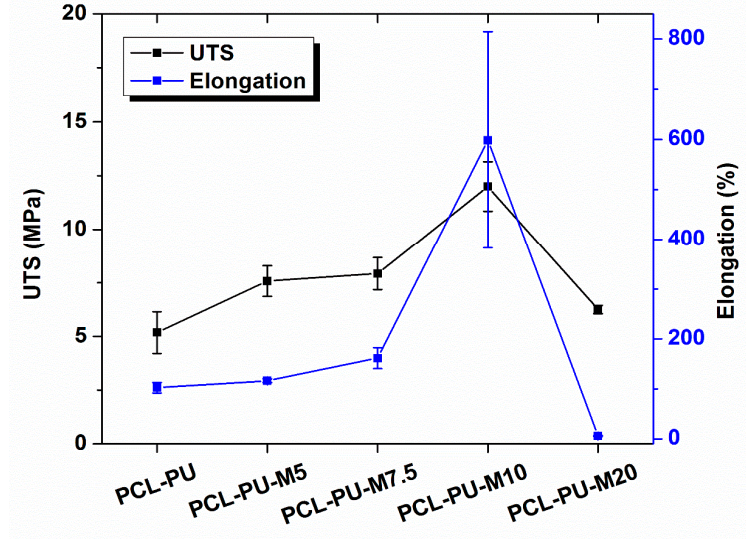

(a)

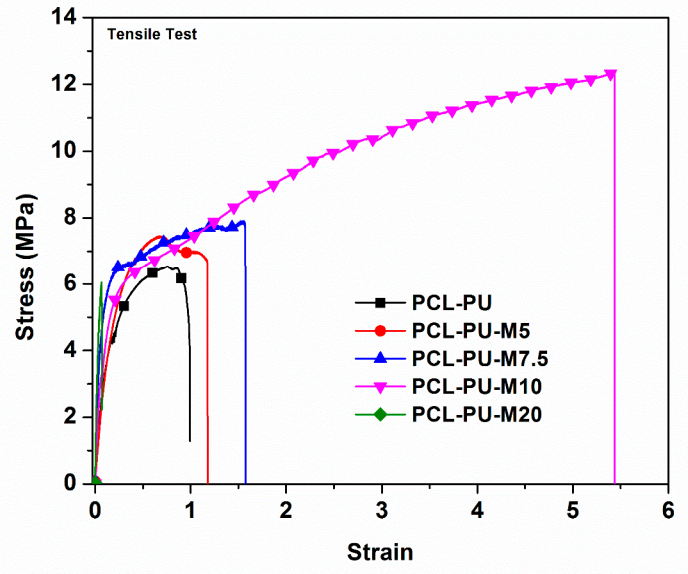

(b)

Figure 5. (a) Ultimate tensile strength (UTS) and elongation at break of the PCL-PU and PCL-PU-Chitosan polyurethane biocomposites and $(\mathbf{b})$ representative stress vs. strain curve for the same.

\subsection{Morphological Analysis of Polyurethane Biocomposites}

The dispersion of the chitosan flakes in the PCL polyurethane matrix resulted in improved mechanical properties, which were analyzed using FESEM. A micrograph of the fractured surface of the PCL-PU and PCL-PU-Chitosan biocomposites, which displays a homogeneous dispersion of the chitosan flakes, is shown in Figure 6. It can be seen from the figure that the chitosan flakes reduced in size during biocomposite fabrication and were found to be around $\sim 150 \mathrm{~nm}$ in width and $\sim 600-1000 \mathrm{~nm}$ in length, whereas the PCL-PU has a relatively smooth surface. 


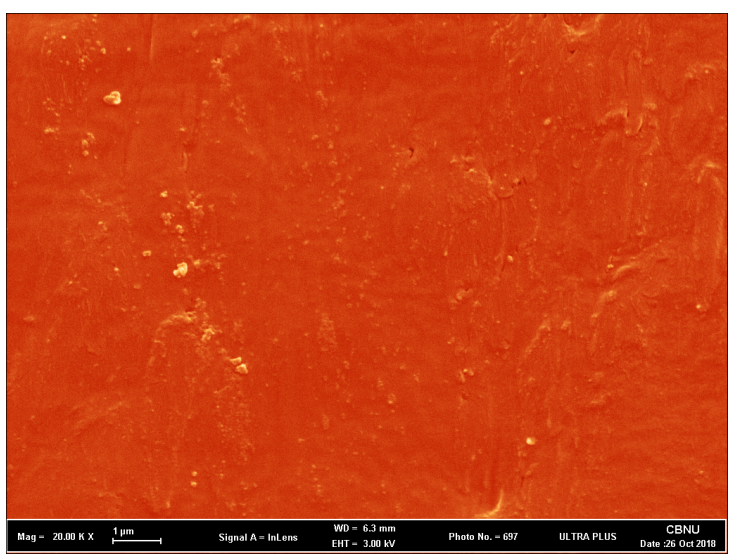

(a)

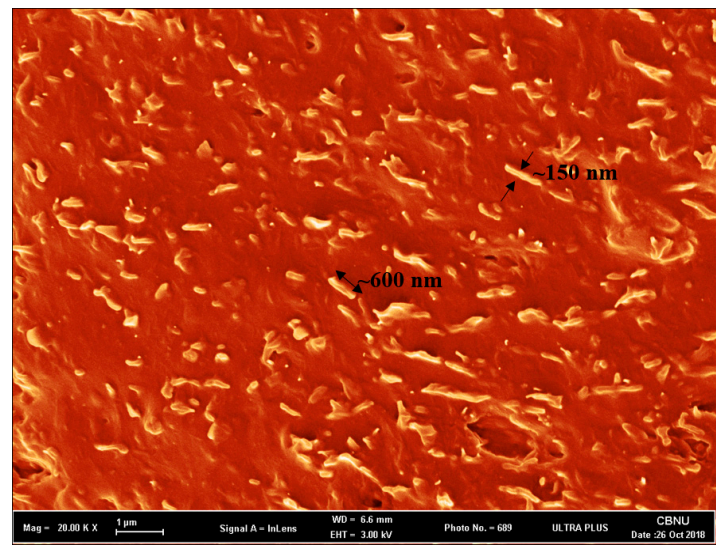

(b)

Figure 6. Representative field emission scanning electron microscope (FESEM) micrographs of (a) the PCL-PU and (b) the PCL-PU-Chitosan biocomposite (Scale bar: $1 \mu \mathrm{m}$ ).

\subsection{Thermal Degradation of Polyurethane Biocomposites}

The thermal behavior of the prepared polyurethane biocomposites was analyzed using TGA and presented in Figure 7. The onset degradation temperature of the chitosan was found to be $135^{\circ} \mathrm{C}$, whereas the maximum degradation rate was observed around $235^{\circ} \mathrm{C}$. It can be surmised that the presence of chitosan may affect the degradation behavior of the biocomposite due to its relatively lower degradation temperature. Conversely, no adverse effect was found in the biocomposite due to the presence of chitosan. The data for the degradation temperature and residue content is listed in Table 1. The onset degradation temperature of the polyurethane biocomposite increased from $310^{\circ} \mathrm{C}$ to $346{ }^{\circ} \mathrm{C}$, alongside the increase in the content of chitosan from $5 \%$ to $10 \%$. Similarly, the maximum degradation temperature improved from $360^{\circ} \mathrm{C}$ to $384{ }^{\circ} \mathrm{C}$, with an upsurge in the content of chitosan from $0 \%$ to $10 \%$. An increase in the content of chitosan to $20 \%$ lead to a reduction in onset degradation $\left(327^{\circ} \mathrm{C}\right)$ as well as maximum degradation temperature $\left(379^{\circ} \mathrm{C}\right)$. The effect of chitosan in the present polyurethane biocomposite can be better understood by estimating the degradation temperature at $10 \%$ weight loss $\left(\mathrm{T}_{10}\right)$. In Table 1 , the $\mathrm{T}_{10}$ for PCL-PU is $309^{\circ} \mathrm{C}$, which reduced to $276^{\circ} \mathrm{C}$ after the addition of $5-10 \%$ chitosan, and again increased to $318^{\circ} \mathrm{C}$. This change could be due to the increased interaction of chitosan and PCL-diol, which stabilizes the polymer system by means of increased cross-linking points. A reduction to $255^{\circ} \mathrm{C}$ was found in a case of $20 \%$ chitosan content, suggesting phase separation. The residual content after thermal degradation, which is a nondegradable carbon residue of chitosan, was also found to increase with an increase in the content of chitosan. Furthermore, it can be derived from the TGA analysis that the presence of chitosan, which has a lower degradation temperature, had no adverse effect on the thermal stability of the polyurethane biocomposite. The crosslinking between the PCL diol and chitosan molecule could be responsible for the stabilization of the polymer system. The crosslinking between the PCL diol and chitosan was also confirmed by the gel content analysis.

Table 1. Thermal transitions and percentage residue for PCL-PU and PCL-PU-Chitosan biocomposites.

\begin{tabular}{cccccc}
\hline Sample Name & $\mathbf{T}_{\text {onset }}\left({ }^{\circ} \mathbf{C}\right)$ & $\mathbf{T}_{\max }\left({ }^{\circ} \mathbf{C}\right)$ & $\mathbf{T}_{\mathbf{1 0}}\left({ }^{\circ} \mathbf{C}\right)$ & $\mathbf{T}_{\mathbf{5 0}}\left({ }^{\circ} \mathbf{C}\right)$ & Residue (\%) \\
\hline Chitosan & 135 & 235 & 135 & 314 & 33.2 \\
PCL-PU & 315 & 360 & 309 & 357 & 0.0 \\
PCL-PU-M5 & 310 & 364 & 276 & 354 & 2.6 \\
PCL-PU-M7.5 & 311 & 366 & 276 & 352 & 4.7 \\
PCL-PU-M10 & 346 & 384 & 318 & 381 & 5.8 \\
PCL-PU-M20 & 327 & 379 & 255 & 379 & 10.8 \\
\hline
\end{tabular}




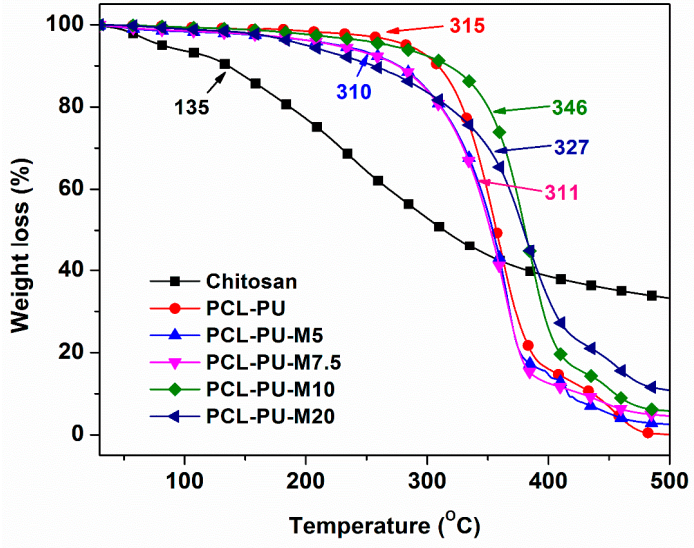

(a)

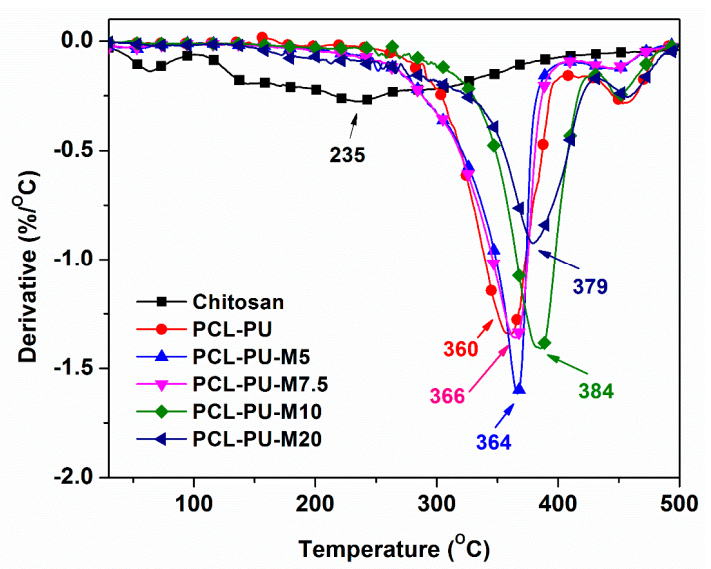

(b)

Figure 7. (a) Weight loss and (b) derivative weight loss of PCL-PU and PCL-PU-Chitosan biocomposite against temperature.

\subsection{Gel Content of Polyurethane Biocomposites}

The samples were suspended in chloroform in order to dissolve the non-crosslinked content, and the insoluble content was measured. A gel content of $\sim 25.4 \%$, which increased to $81.2 \%$ with an increase in the content of chitosan from $0 \%$ to $20 \%$ (Figure 8 ), was found for the PCL-PU. This improvement in the gel content suggests an enhancement in cross-linking that reduced the solubility of the polymer system. The presence of chitosan provided the cross-linking points which led to an increase in the gel content.

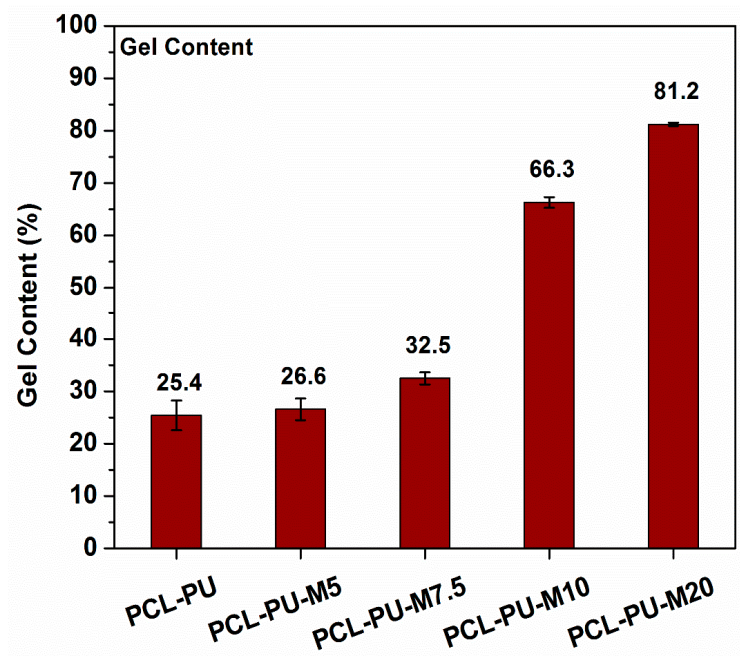

Figure 8. Gel content in the PCL-PU and PCL-PU-Chitosan biocomposites in chloroform.

\subsection{Shape Memory Effect of PCL Based Polyurethane Biocomposites}

Figure 9 demonstrates the shape memory effect of the prepared polyurethane biocomposite in a dry condition where the polyurethanes were initially fixed by heating them to $50{ }^{\circ} \mathrm{C}$ followed by cooling them to room temperature. It was found that the time required for shape recovery after the fixing was quite similar for the PCL-PU and PCL-PU-Chitosan biocomposites. The shape recovery of the biocomposite was also demonstrated in a wet condition, which is shown in Figure 10. A random shaped polymer sheet was punched with circular shapes and mechanically stretched at $50^{\circ} \mathrm{C}$ followed by cooling to room temperature. The mechanical stretching led to a permanent deformation of the circled shapes, which were recovered by approximately $100 \%$ by placing the sample in warm water at 
$50{ }^{\circ} \mathrm{C}$. For the quantitative analysis of the shape memory behavior of the polyurethane biocomposite, the shape fixing ratio and shape recovery ratio was measured and is presented in Table 2. It is seen that the shape fixing ratio improved from $~ 53 \%$ to approximately $100 \%$ after the incorporation of $10 \%$ chitosan. Similarly, the shape recovery ratio was found to be improved from $\sim 88 \%$ to $\sim 100 \%$.

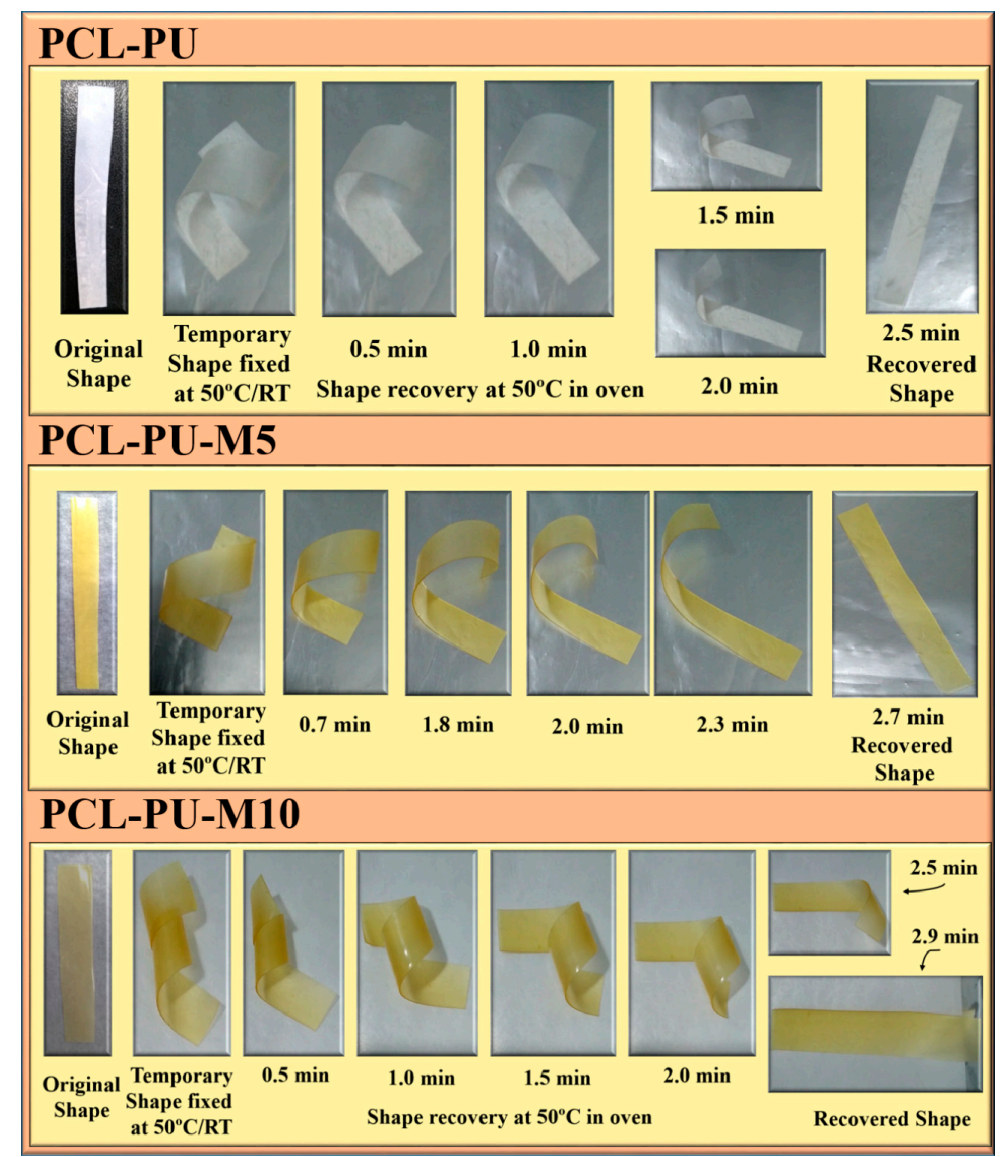

Figure 9. Demonstration of the shape memory effect in the PCL-PU-Chitosan biocomposite in a dry condition.

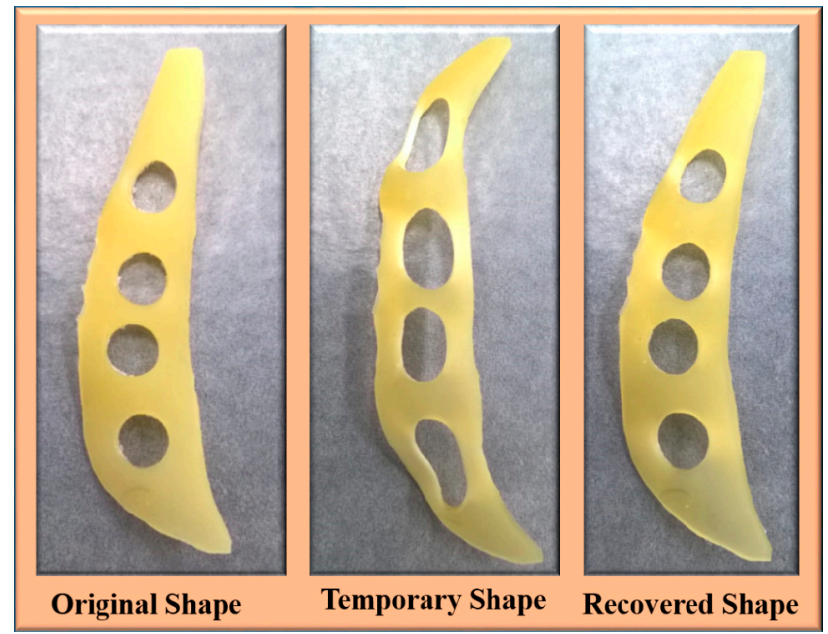

Figure 10. The shape memory ability of the prepared random shaped chitosan polyurethane composite for grip application (Temporary shape at room temperature using tensile force; recovered shape in water (wet condition) at $50{ }^{\circ} \mathrm{C}$ within $5 \mathrm{~s}$ ). 
Table 2. Shape fixing and shape recovery ratios of the PCL-PU and PCL-PU-Chitosan polyurethane biocomposites.

\begin{tabular}{ccc}
\hline Polyurethane Samples & Shape Fixing Ratio (\%) & Shape Recovery Ratio (\%) \\
\hline PCL-PU & $53.1 \pm 6.2$ & $88.6 \pm 1.3$ \\
PCL-PU-M5 & $81.2 \pm 2.6$ & $90.8 \pm 1.2$ \\
PCL-PU-M7.5 & $93.4 \pm 5.0$ & $98.5 \pm 0.5$ \\
PCL-PU-M10 & $99.5 \pm 0.4$ & $99.3 \pm 0.7$ \\
PCL-PU-M20 & Not stretchable & Not stretchable \\
\hline
\end{tabular}

The mechanical analysis revealed that the toughness of the materials was drastically improved, which could be the result of the increased crosslinked nodes in the polymer system. The shape recovery of the prepared material from an elongated ( $500 \%$ strain) or permanently deformed condition is shown in Figure 11.

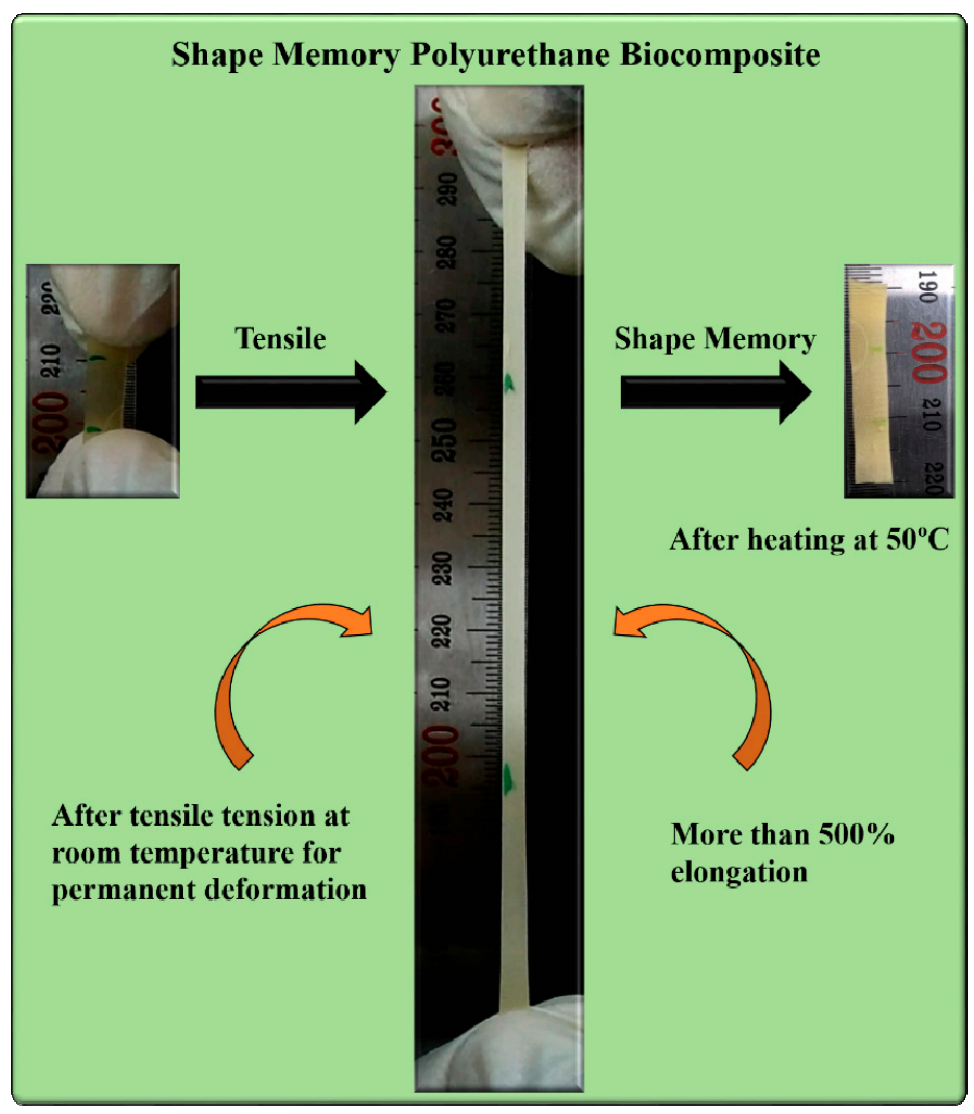

Figure 11. Shape memory behavior of the polyurethane chitosan biocomposite after tensile tension.

The coiling and uncoiling of the PCL chains could be responsible for the shape memory ability, which greatly corresponds to the crosslink content in the polymer matrix. It was found that the polyurethane biocomposite with chitosan retains its temporary shape even after the removal of stress and sustained restraint. The developed restraint in the shape memory polyurethane biocomposite due to tensile pull is possibly released during thermal softening around the melting of the PCL crystallites. An upsurge in the temperature triggers the melting of PCL crystallites which are formed due to a stress induced crystallization phenomenon during tensile pull, and the material tends to recover its original shape. The chitosan nanoflakes work as rigid crosslinking nodes covalently bonded between extendable PCL chains. These cross-linking nodes could be responsible for putting back polymer chains in response to an external stimulus. On the other hand, the formation of crystallites facilitates a 
proficient and quick formation of the switching domain, as observed in the DSC analysis (the melting of PCL crystallites in the range of $40-50{ }^{\circ} \mathrm{C}$ ) and also confirmed from the X-ray analysis.

XRD analysis of the stretched and non-stretched (PCL-PU-chitosan) samples is shown in Figure 3b. It can be seen that the intensity of the characteristic peaks for PCL at $21.3^{\circ}$ and $23.6^{\circ}$ is enhanced, suggesting that the crystallinity of the biocomposite is increased. The enhancement in the crystallinity could be the consequence of stress induced crystallization during tensile work. The uncoiling of coiled PCL chains, and arrangement of the same, increases the crystallinity of the biocomposite and possibly enhances the shape memory even after permanent deformation. Also, the shape recovery phenomenon of PCL based chitosan polyurethane biocomposite is demonstrated in Video S1.

\section{Conclusions}

We have successfully demonstrated the fabrication of a PCL based shape memory polyurethane biocomposite via in situ incorporation of chitosan. The developed biocomposite with $10 \%$ chitosan content had $\sim 130 \%$ enhancement in ultimate tensile strength and more than $500 \%$ elongation at break in comparison to pristine PCL-PU. The electron microscopic analysis confirmed the homogeneous distribution of chitosan flakes with $\sim 150 \mathrm{~nm}$ width in the polymer matrix. X-ray and DSC analysis confirmed the presence of PCL crystallites, which may act as a switching point for the shape memory behavior. X-ray diffraction analysis also confirmed the development of crystallites, resulting from a stress induced crystallization process during tensile pull, which may retain the shape and melting of the crystallites, thereby stimulating shape recovery (with $\sim 100 \%$ shape recovery ratio), even after permanent deformation. The biodegradable polyurethane biocomposite also demonstrates relatively higher thermal stability $\left(\mathrm{T}_{\max }\right.$ at $\sim 360{ }^{\circ} \mathrm{C}$ ). Overall, the fabricated shape memory polyurethane biocomposite possesses a unique shape memory behavior, even after permanent deformation to more than a $500 \%$ strain, which has extreme potential in several biomedical applications.

Supplementary Materials: The following are available online at http://www.mdpi.com/2079-4991/9/ 2/225/s1, Video S1: Video demonstrating the shape recovery phenomenon of PCL based chitosan polyurethane biocomposite.

Author Contributions: A.G. developed and designed the research, executed experiments, analyzed data and wrote the manuscript. B.S.K. designed the research and discussed the results. All authors reviewed the manuscript.

Funding: This work was supported by Post-Doctoral Fellowship Program funded by the Ministry of Education of the Republic of Korea through the Chungbuk National University in 2018-2019 and the National Research Foundation of Korea (NRF-2017R1A2B4002371).

Conflicts of Interest: The authors declare no conflict of interest.

\section{References}

1. Wadood, A. Brief overview on nitinol as biomaterial. Adv. Mat. Sci. Eng. 2016, 2016, 9. [CrossRef]

2. Ortega, A.M.; Yakacki, C.M.; Dixon, S.A.; Likos, R.; Greenberg, A.R.; Gall, K. Effect of crosslinking and long-term storage on the shape-memory behavior of (meth)acrylate-based shape-memory polymers. Soft Matter 2012, 8, 7381-7392. [CrossRef]

3. Xiao, X.; Kong, D.; Qiu, X.; Zhang, W.; Liu, Y.; Zhang, S.; Zhang, F.; Hu, Y.; Leng, J. Shape memory polymers with high and low temperature resistant properties. Sci. Rep. 2015, 5, 14137. [CrossRef] [PubMed]

4. Memarian, F.; Fereidoon, A.; Ghorbanzadeh Ahangari, M. Effect of acrylonitrile butadiene styrene on the shape memory, mechanical, and thermal properties of thermoplastic polyurethane. J. Vinyl Addit. Techn. 2018, 24, E96-E104. [CrossRef]

5. Sakurai, K.; Tanaka, H.; Ogawa, N.; Takahashi, T. Shape-memorizable styrene-butadiene block copolymer. I. Thermal and mechanical behaviors and structural change with deformation. J. Macromol. Sci. B 1997, 36, 703-716. [CrossRef]

6. Hu, J.; Yang, Z.; Yeung, L.; Ji, F.; Liu, Y. Crosslinked polyurethanes with shape memory properties. Polym. Int. 2005, 54, 854-859. [CrossRef] 
7. Li, P.; Han, Y.; Wang, W.; Liu, Y.; Jin, P.; Leng, J. Novel programmable shape memory polystyrene film: A thermally induced beam-power splitter. Sci. Rep. 2017, 7, 44333. [CrossRef] [PubMed]

8. Xie, T. Recent advances in polymer shape memory. Polymer 2011, 52, 4985-5000. [CrossRef]

9. Behl, M.; Lendlein, A. Shape-memory polymers. Mater. Today 2007, 10, 20-28. [CrossRef]

10. Seymour, R.B.; Kauffman, G.B. Polyurethanes: A class of modern versatile materials. J. Chem. Edu. 1992, 69, 909. [CrossRef]

11. Akindoyo, J.O.; Beg, M.D.H.; Ghazali, S.; Islam, M.R.; Jeyaratnam, N.; Yuvaraj, A.R. Polyurethane types, synthesis and applications-A review. RSC Adv. 2016, 6, 114453-114482. [CrossRef]

12. Puszka, A.; Kultys, A. New thermoplastic polyurethane elastomers based on aliphatic diisocyanate. J. Therm. Anal. Calorim. 2017, 128, 407-416. [CrossRef]

13. Mi, H.-Y.; Jing, X.; Napiwocki, B.N.; Hagerty, B.S.; Chen, G.; Turng, L.-S. Biocompatible, degradable thermoplastic polyurethane based on polycaprolactone-block-polytetrahydrofuran-block-polycaprolactone copolymers for soft tissue engineering. J. Mat. Chem. B 2017, 5, 4137-4151. [CrossRef] [PubMed]

14. Ping, P.; Wang, W.; Chen, X.; Jing, X. Poly( $\varepsilon$-caprolactone) polyurethane and its shape-memory property. Biomacromolecules 2005, 6, 587-592. [CrossRef]

15. Lendlein, A.; Langer, R. Biodegradable, elastic shape-memory polymers for potential biomedical applications. Science 2002, 296, 1673-1676. [CrossRef] [PubMed]

16. The future of plastic. Nat. Commun. 2018, 9, 2157. [CrossRef] [PubMed]

17. Gross, R.A.; Kalra, B. Biodegradable polymers for the environment. Science 2002, 297, 803-807. [CrossRef] [PubMed]

18. Malikmammadov, E.; Tanir, T.E.; Kiziltay, A.; Hasirci, V.; Hasirci, N. PCL and PCL-based materials in biomedical applications. J. Biomat. Sci. Polym. Edit. 2018, 29, 863-893. [CrossRef] [PubMed]

19. Gupta, A.; Katiyar, V. Cellulose functionalized high molecular weight stereocomplex polylactic acid biocomposite films with improved gas barrier, thermomechanical properties. ACS Sustain. Chem. Eng. 2017, 5, 6835-6844. [CrossRef]

20. Pack, S.; Lewin, M.; Rafailovich, M.H. A review of engineering biodegradable polymer blends: Morphology, mechanical property, and flame retardancy. In Fire and Polymers VI: New advances in Flame Retardant Chemistry and Science; American Chemical Society: Washington, DC, USA, 2012; Volume 1118, pp. 427-443.

21. Yılmaz, M.; Eğri, S.; Yıldız, N.; Çalımlı, A.; Pişkin, E. Ring-opening copolymerization of 1-lactide and $\mathcal{E}$-caprolactone in supercritical carbon dioxide using triblock oligomers of caprolactone and PEG as stabilizers. Polym. J. 2011, 43, 785. [CrossRef]

22. Gupta, A.; Prasad, A.; Mulchandani, N.; Shah, M.; Ravi Sankar, M.; Kumar, S.; Katiyar, V. Multifunctional nanohydroxyapatite-promoted toughened high-molecular-weight stereocomplex poly(lactic acid)-based bionanocomposite for both 3D-printed orthopedic implants and high-temperature engineering applications. ACS Omega 2017, 2, 4039-4052. [CrossRef] [PubMed]

23. Gupta, A.; Pal, A.K.; Woo, E.M.; Katiyar, V. Effects of amphiphilic chitosan on stereocomplexation and properties of poly(lactic acid) nano-biocomposite. Sci. Rep. 2018, 8, 4351. [CrossRef] [PubMed]

24. Flesch, C.; Delaite, C.; Dumas, P.; Bourgeat-Lami, E.; Duguet, E. Grafting of poly(e-caprolactone) onto maghemite nanoparticles. J. Polym. Sci. A Polym. Chem. 2004, 42, 6011-6020. [CrossRef]

25. Peponi, L.; Navarro-Baena, I.; Sonseca, A.; Gimenez, E.; Marcos-Fernandez, A.; Kenny, J.M. Synthesis and characterization of PCL-PLLA polyurethane with shape memory behavior. Eur. Polym. J. 2013, 49, 893-903. [CrossRef]

26. Lopez-Figueras, L.; Navascues, N.; Irusta, S. Polycaprolactone/mesoporous silica mcm-41 composites prepared by in situ polymerization. Particuology 2017, 30, 135-143. [CrossRef]

27. Ahmad, A.F.; Abbas, Z.; Aziz, S.A.; Obaiys, S.J.; Zainuddin, M.F. Synthesis and characterisation of nickel oxide reinforced with polycaprolactone composite for dielectric applications by controlling nickel oxide as a filler. Results Phys. 2018, 11, 427-435. [CrossRef]

28. Sarasam, A.; Madihally, S.V. Characterization of chitosan-polycaprolactone blends for tissue engineering applications. Biomaterials 2005, 26, 5500-5508. [CrossRef] [PubMed]

29. Grząbka-Zasadzińska, A.; Klapiszewski, Ł.; Borysiak, S.; Jesionowski, T. Thermal and mechanical properties of silica-lignin/polylactide composites subjected to biodegradation. Materials 2018, 11, 2257. [CrossRef]

30. Duan, T.; Lv, Y.; Xu, H.; Jin, J.; Wang, Z. Structural effects of residual groups of graphene oxide on poly( $\varepsilon$-caprolactone)/graphene oxide nanocomposite. Crystals 2018, 8, 270. [CrossRef] 
31. Benkaddour, A.; Jradi, K.; Robert, S.; Daneault, C. Grafting of polycaprolactone on oxidized nanocelluloses by click chemistry. Nanomaterials 2013, 3, 141-157. [CrossRef]

32. Thompson, Z.; Rahman, S.; Yarmolenko, S.; Sankar, J.; Kumar, D.; Bhattarai, N. Fabrication and characterization of magnesium ferrite-based PCL/Aloe vera nanofibers. Materials 2017, 10, 937. [CrossRef]

33. Xu, T.; Jin, W.; Wang, Z.; Cheng, H.; Huang, X.; Guo, X.; Ying, Y.; Wu, Y.; Wang, F.; Wen, Y.; et al. Electrospun CuO-nanoparticles-modified polycaprolactone @polypyrrole fibers: An application to sensing glucose in saliva. Nanomaterials 2018, 8, 133.

34. Gupta, A.; Mulchandani, N.; Shah, M.; Kumar, S.; Katiyar, V. Functionalized chitosan mediated stereocomplexation of poly(lactic acid): Influence on crystallization, oxygen permeability, wettability and biocompatibility behavior. Polymer 2018, 142, 196-208. [CrossRef]

35. Mourya, V.K.; Inamdar, N.N. Chitosan-modifications and applications: Opportunities galore. React. Funct. Polym. 2008, 68, 1013-1051. [CrossRef]

36. Leite, Á.J.; Caridade, S.G.; Mano, J.F. Synthesis and characterization of bioactive biodegradable chitosan composite spheres with shape memory capability. J. Non-Cryst. Solids 2016, 432, 158-166. [CrossRef]

37. Bao, M.; Zhou, Q.; Dong, W.; Lou, X.; Zhang, Y. Ultrasound-modulated shape memory and payload release effects in a biodegradable cylindrical rod made of chitosan-functionalized PLGA microspheres. Biomacromolecules 2013, 14, 1971-1979. [CrossRef] [PubMed]

38. Zhang, F.; Zhou, T.; Liu, Y.; Leng, J. Microwave synthesis and actuation of shape memory polycaprolactone foams with high speed. Sci. Rep. 2015, 5, 11152. [CrossRef]

39. Shou, Q.; Uto, K.; Iwanaga, M.; Ebara, M.; Aoyagi, T. Near-infrared light-responsive shape-memory poly( $\varepsilon$-caprolactone) films that actuate in physiological temperature range. Polym. J. 2014, 46, 492. [CrossRef]

40. Barikani, M.; Honarkar, H.; Barikani, M. Synthesis and characterization of polyurethane elastomers based on chitosan and poly(E-caprolactone). J. Appl. Polym. Sci. 2009, 112, 3157-3165. [CrossRef]

41. Van de Velde, K.; Kiekens, P. Structure analysis and degree of substitution of chitin, chitosan and dibutyrylchitin by FT-IR spectroscopy and solid state ${ }^{13} \mathrm{C}$ NMR. Carbohyd. Polym. 2004, 58, 409-416. [CrossRef]

42. Baji, A.; Wong, S.-C.; Liu, T.; Li, T.; Srivatsan, T.S. Morphological and X-ray diffraction studies of crystalline hydroxyapatite-reinforced polycaprolactone. J. Biomed. Mater. Res. B Appl. Biomater. 2007, 81B, 343-350. [CrossRef] [PubMed]

43. Yuan, Y.; Chesnutt, B.M.; Haggard, W.O.; Bumgardner, J.D. Deacetylation of chitosan: Material characterization and in vitro evaluation via albumin adsorption and pre-osteoblastic cell cultures. Materials 2011, 4, 1399. [CrossRef] [PubMed]

44. Wan, Y.; Huang, J.; Zhang, J.; Yin, D.; Zheng, Z.; Liao, C.; Sun, S. Investigation of mechanical properties and degradability of multi-channel chitosan-polycaprolactone/collagen conduits. Polym. Degrad. Stabil. 2013, 98, 122-132. [CrossRef]

(C) 2019 by the authors. Licensee MDPI, Basel, Switzerland. This article is an open access article distributed under the terms and conditions of the Creative Commons Attribution (CC BY) license (http:/ / creativecommons.org/licenses/by/4.0/). 